\title{
AVALIAÇÃO DA PROPOSTA DE CONSTRUÇÃO DE UM CURRÍCULO INTERDISCIPLINAR NUMA ESCOLA TÉCNICA DE SAÚDE
}

\section{ASSESSMENT OF THE PROPOSAL TO CONSTRUCT A INTERDISCIPLINARY CURRICULUM IN A TECHNICAL HEALTH SCHOOL}

\author{
Paulo Gilberto Simões Dávila ${ }^{1}$ \\ Rochele de Quadros Loguercio ${ }^{2}$ \\ José Claudio Del Pino ${ }^{3}$ \\ Fabiano da Silveira Santos 4
}

Resumo Este trabalho busca propiciar espaços para a formação dos professores, agregando a prática por eles desenvolvida ao plano político-pedagógico da escola e aos entendimentos sobre as diferentes formas e níveis de integração curricular possíveis. Nesse processo foram pesquisados os entendimentos de inter/multi/pluri/transdisciplinariedade e a forma pela qual ela poderia ser efetivada numa realidade educacional de escola técnica.

Palavras-chave interdisciplinaridade; escola técnica; educação e saúde.
Abstract This work aims to provide spaces for the training and education of teachers, adding the practices they developed to the school's politicalpedagogical plan and to the views of the various forms and levels of possible curricular integration. The authors researched inter/multi/pluri/transdisciplinarity and the manner in which it could be achieved in the educational reality of a technical school.

Keywords interdisciplinarity; technical school; education and health. 


\section{Situando a pesquisa}

Desenvolveu-se na Área de Educação Química uma parceria com a Escola Técnica de Saúde (ETS) da Secretaria de Educação do Rio Grande do Sul (SE-RS), no Hospital de Clínicas de Porto Alegre (HCPA), para a construção de uma proposta de estruturação dos currículos dos cursos técnicos em Patologia Clínica, Nutrição e Dietética, Administração Hospitalar e Radiologia Médica, numa perspectiva da interdisciplinaridade.

As atividades foram desenvolvidas com o objetivo de operacionalizar o projeto político-pedagógico já construído na escola, buscando orientar as ações para uma escola técnica, não tecnicista, onde se pudesse gerar um processo educativo em consonância com os princípios e diretrizes do que se entendia como educação em saúde.

Pressupostos construtivistas e sociointeracionistas deram sustentação a este projeto político-pedagógico, que visou romper com o modelo mecanicista-tecnicista, fruto do paradigma cartesiano, responsável pelas visões fragmentárias e reducionistas presentes nas áreas da educação e da saúde. Nesse sentido, os referidos pressupostos quebram a hegemonia de um conhecimento estático e valorizam a integração e produção de saberes na própria escola. A emergência de um outro paradigma possibilitou a construção de uma práxis cujas alternativas didático-pedagógicas tinham como pressuposto contrapor: reprodução e inovação; discriminação e inclusão; certeza e dúvida; fragmentação e integração; competição e cooperação, entre outros valores capazes de dinamizar a busca e alimentar o sonho de que uma nova educação é possível (Escola Técnica de Saúde do HCPA/SERS, 2001).

Nesta perspectiva, o processo de planejamento didático-pedagógico, ocorreu através de dois espaços de discussão: nos três núcleos de competências específicos (comunicação, ciência e tecnologia, sociedade e cidadania), com suas disciplinas buscando a interação entre o ensino médio e o ensino profissionalizante; e nos encontros dos diferentes núcleos de competências - constituidores da estrutura organizacional da ETS.

O Diagrama 1 indica a relação entre os três núcleos compondo o currículo interdisciplinar estruturado, de acordo com o projeto político-pedagógico da escola; o Diagrama 2 mostra como um desses núcleos é composto por disciplinas afins. Os núcleos de competência gestam habilidades e competências específicas nos três campos de saberes próximos. Pretende-se, através dos núcleos, integrar disciplinas no seu interior e propor a construção de um currículo interdisciplinar. 


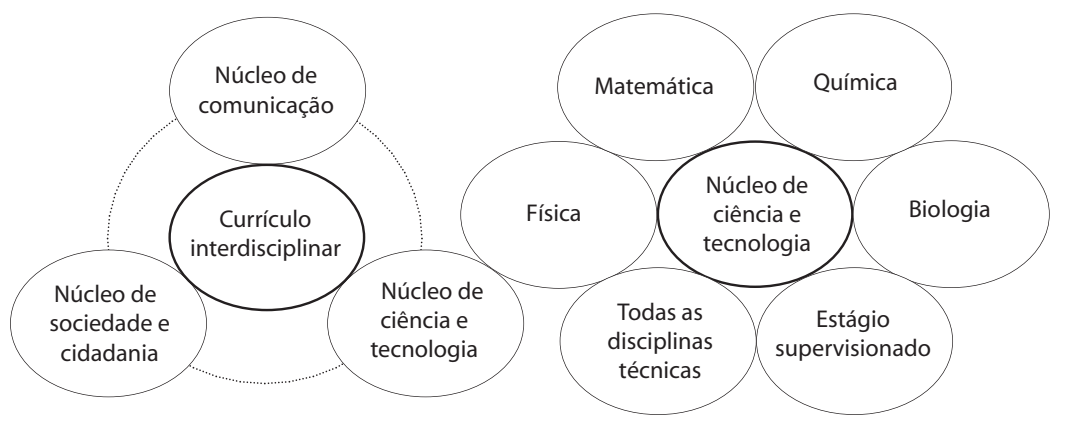

Foi dada ênfase nas interfaces existentes entre os núcleos, buscando romper os limites próprios de cada núcleo e, assim, priorizando os entendimentos de educação em saúde de uma forma ampliada pela interface entre todas as disciplinas.

\section{O referencial teórico: concepções sobre disciplinaridade}

Durante as duas últimas décadas do século $\mathrm{XX}$, ampliaram-se as discussões sobre os currículos, indo além das já tradicionais sobre a sua estrutura, conteúdos e metodologias didáticas e irrompendo para a problematização da estrutura das disciplinas, seus limites e fronteiras, a inter-relação com disciplinas afins, a capacidade de responder a questões de caráter amplo, entre outras possibilidades. As formas de nomear as diferentes propostas curriculares se multiplicam com significados não tão diferentes entre si, porém é importante perceber de onde emergem estas novas possibilidades de trabalho e como se formam, constituem e passam a pertencer à linguagem 'comum' das discussões em educação.

Os termos interdisciplinaridade, multidisciplinaridade, pluridisciplinaridade, transdisciplinaridade 5 aparecem em inúmeras publicações acadêmicas, como monografias, dissertações, teses, bem como nos meios de comunicação, nos discursos políticos sobre educação, nas escolas desde a educação infantil até a educação profissional e tecnológica, "espalha-se como se espalharam as idéias sobre construtivismo: como uma mancha de óleo" (Delval, 1997, p. 1).

Na maioria das vezes, estes termos são de significado turvo, impreciso, não resistindo a questionamentos epistemológicos simples. Percebe-se, 
hoje, termos gastos e um significante vazio. Como ocorreu com o construtivismo, a inter/multi/pluri/transdisciplinaridade é entendida tão diferentemente que diz pouco e, por isso mesmo, talvez se esteja perdendo de novo a possibilidade de construir um outro currículo.

Ao se analisarem os entendimentos de alguns autores sobre interdisciplinaridade, verifica-se a multiplicidade de definições para o termo, da mesma forma que para suas demais variantes ('multi', 'pluri', 'trans').

Japiassu indica que interdisciplinaridade é caracterizada pela intensidade das trocas entre os especialistas e pelo grau de integração real das disciplinas, no interior de um projeto específico de pesquisa. Neste sistema, a colaboração entre as diversas disciplinas ou entre os setores heterogêneos de uma mesma ciência conduz a interações propriamente ditas, isto é, a uma certa reciprocidade nos intercâmbios, de tal forma que, no final do processo interativo, cada disciplina saia enriquecida (Japiassu, 1976).

Conforme Apostel, Berger e Michaud, em L'interdisciplinarité (apud Fazenda, 1996), interdisciplinaridade é a interação existente entre duas ou mais disciplinas. Essa interação pode ir da simples comunicação de idéias à integração mútua dos conceitos diretores da epistemologia, da terminologia, da metodologia, dos procedimentos, dos dados e da organização referentes ao ensino e à pesquisa. Um grupo interdisciplinar compõe-se de pessoas que receberam sua formação em diferentes domínios do conhecimento com seus métodos, conceitos, dados e termos próprios.

A problemática sobre educação não pode ignorar as filosofias e epistemologias das construções destes conceitos, pois não se limita apenas a uma questão semântica; trata-se do que fazemos com os nossos termos, como nos apropriamos dos discursos e o que dizemos quando falamos sobre algo. E, ainda, da estrutura social que se afigura, com suas mudanças e transversalidade em termos de informação e processamento dessas na era global.

Associada à problemática do entendimento dos termos está a desestruturação de um sistema disciplinar secular. No dizer de Torres Santomé (1994), a ruptura de fronteiras entre as disciplinas (corolário da multiplicidade de áreas científicas e de alguns modelos de sociedade cada vez mais abertos, da desaparição de barreiras na comunicação e mundialização da informação) vem obrigando a uma tomada de consideração de modelos de análise muito mais potentes que os que eram típicos de uma única especialização disciplinar.

Como destaca Arnay (1997), qualquer tentativa de mudar a rigidez conceitual e temática do currículo se limita a contemplar tímidos retoques sempre e quando estes não afetam a "essência disciplinar". Arnay continua a assertiva, enfocando um dos possíveis entraves a esta mudança que ele define como sendo a defesa corporativista por parte de certos grupos de uma determinada visão disciplinar do conhecimento. 
Portanto, as dificuldades para aplicar as teorias propostas a situações reais de operacionalização do currículo nos diferentes níveis de escolaridade passam pelo entendimento do que efetivamente se quer fazer tanto quanto pela capacidade de aceitar as mudanças propostas. Um indicativo de quão difíceis podem ser estas mudanças está na constatação de que as experiências relatadas como bem sucedidas envolvem atividades paraescolares ou extracurriculares, como por exemplo de educação e alfabetização indígena, de alfabetização de jovens e adultos, de educação ambiental e educação sexual.

Uma alternativa para fazer diferença na escola tradicional é a formação de equipes constituintes de núcleos de competência envolvendo professores das diferentes áreas do conhecimento que tomam parte do currículo da escola, pois os núcleos fazem o primeiro rompimento de fronteiras disciplinares em disciplinas com alguns objetivos comuns para depois promoverem a interdisciplinaridade do currículo.

\section{A formação de professores}

Deve-se considerar que a transposição para a realidade de escola, como neste projeto de investigação junto à ETS, exige a abertura de um espaço de formação dos professores, onde justamente deverão ser expostas as suas concepções sobre inter/multi/pluri/transdisciplinaridade e, numa reflexão coletiva com seus pares, se realizar um aclaramento sobre tais concepções. Este espaço se constitui numa estratégia de formação de professores numa perspectiva da investigação na escola, onde se considera que este procedimento se fundamenta na concepção de que o desenvolvimento de pesquisas que integram universidade e escola tem um comprometimento de serem educativas e formativas dos professores envolvidos de ambas instituições de ensino. Requer um modelo de investigação: que esteja fundamentado na ação pedagógica do professor Thiollent (1986), considerado como um intelectual (Giroux, 1997); que considere o mesmo como investigador na sua realidade de escola (Cañal et al., 1997; Demo, 1998; Porlán e Riveiro, 1998); que se aproprie da ação investigadora como um processo de natureza construtivista do conhecimento científico (Carretero, 1997; Porlán, García e Canãl, 1997; Schön, 2000).

Portanto, em qualquer processo com esta natureza se exige obrigatoriamente o envolvimento do professor, pois é ele o principal articulador do processo de ensino e de aprendizagem. Também se entende que qualquer mudança desejada para maior qualificação científica, social e política do ensino deve, impreterivelmente, passar pelo professor com 
efetiva atuação nas escolas, preferentemente da rede pública de educação (Del Pino et al., 1995). Diferentemente do que tem acontecido na maioria dos projetos, em que pacotes 'educacionais' de gabinete são, por imposição, levados ao conhecimento do professor que deles deve apropriarse e assumir.

Os problemas detectados no dia-a-dia de uma sala de aula podem ter suas causas atribuídas a diferentes situações concretas ou subjetivas, mas que não podem ser definidas fora de seus contextos e generalizadas indiscriminadamente. Desta forma, procuram-se situações que promovam uma ação de reflexão, por parte do professor, uma reflexão sobre os saberes que envolvem sua prática, saberes que podem ser oriundos da formação profissional, dos saberes das disciplinas, dos currículos e da experiência, com os quais mantêm diferentes relações (Tardif, 1991).

Neste sentido, portanto, almeja-se desenvolver o projeto na realidade espacial da ETS, com seus professores envolvidos na construção e aplicação da proposta curricular interdisciplinar, imersos na dimensão da investigação e da prática reflexiva nas suas diferentes variantes relacionais, conforme Schön (2000), conhecer-na-ação, reflexão-na-ação e reflexão sobre a reflexão-na-ação, constituindo-se esta ação numa estratégia de formação de professores na sua realidade de escola.

Com esse objetivo se trabalhou com os professores os conceitos sobre inter/multi/pluri/transdisciplinaridade, em busca de uma definição deles sobre o entendimento de interdisciplinaridade, termo que consta no PPP da escola e sobre os quais os professores orientariam suas práticas curriculares. Este conceito, como mostramos acima, pode ser interpretado de formas diferentes, como por exemplo em Japiassu e Fazenda.

\section{A formação do técnico em saúde}

Uma produção como descrita acima, associada e consolidada na dinâmica de sala de aula, tem significativas contribuições na formação dos profissionais técnicos em saúde numa perspectiva que vê o técnico não apenas como um simples especialista executor de procedimentos padronizados, mas como um indivíduo capaz de interagir com seu conhecimento no sentido de aprimorar ou desenvolver técnicas ou produtos e ainda apropriar-se da dimensão sociopolítica do seu trabalho.

A educação através da pesquisa se constitui numa possibilidade concreta de entender que o universo de uma sala de aula não está restrito à mera repetição-memorização de conhecimentos definidos a priori. Que tal conhecimento é produzido e transformado dentro de cada sala de aula. Entender, por outro lado, que a capacidade de descentramento pode ser 
apreendida, e imbricada nessa aprendizagem está a capacidade de criticar e refletir sobre a própria prática, possibilitando um agir mais crítico e criativo. Neste sentido pode-se pensar nesta pesquisa como possibilidade de desenvolvimento pessoal e de transformação da realidade circunscrita à escola. Transformação esta que se concretiza na parceria professor-aluno, com ênfase numa nova relação pedagógica, superando a aula copiada, substituindo-a pela construção do conhecimento. A sala de aula convertese num espaço de criticidade, autonomia e transformação do currículo, da realidade (Demo, 1992 e 1998).

A pesquisa realizada na escola segue na esteira das propostas de ciência, tecnologia e sociedade (CTS), que estão vinculadas à educação científica do cidadão, que significa o ensino do conteúdo das diferentes áreas do conhecimento no contexto do seu meio tecnológico e social. Os estudantes tendem a integrar a sua compreensão do mundo natural com o mundo construído pelo homem (tecnologia) e o seu mundo social do dia-a-dia (sociedade). O objetivo principal dos cursos com preocupação central para a formação da cidadania se refere ao desenvolvimento da capacidade de tomada de decisão como uma de suas ênfases. Esta se relaciona à solução de problemas da vida real que envolvem aspectos sociais, tecnológicos, econômicos e políticos, o que significa preparar o indivíduo para participar ativamente na sociedade. O conhecimento está diretamente vinculado à problemática social: qualidade de vida das pessoas, efeitos ambientais de aplicações tecnológicas, decisões solicitadas aos indivíduos quanto ao emprego de tais tecnologias, industrialização, consumo, ética (Santos e Schnetzler, 1997; Mol e Santos, 1998).

Portanto, nestas perspectivas, da pesquisa e dos movimentos de CTS, devem se estruturar cursos da natureza dos que a ETS tem oferecido, cursos para formar um técnico diferenciado, com uma expectativa de que o quadro docente conduza suas ações na execução do novo, refletindo sobre a ação e o planejado, assim como os jovens estudantes que estão realizando sua formação têm o direito, e talvez a expectativa, de receber informações com a qualidade de uma sociedade tecnológica, informatizada, mas carente do vetor social.

\section{Aspectos metodológicos}

Os procedimentos metodológicos para a obtenção de informações sobre o processo de construção da proposta de estruturação do currículo, de sua execução e da formação dos professores da ETS/HCPA estão organizados em diferentes etapas no projeto. Aqui se apresentam aquelas relativas à estruturação da proposta curricular. 
Utilizou-se o espaço das reuniões pedagógicas da escola, realizadas semanalmente com duração de duas horas, para a discussão com os professores da estruturação da proposta pedagógica da escola no âmbito da construção de um currículo interdisciplinar6 nos cursos técnicos oferecidos.

Analisaram-se as concepções dos professores sobre disciplinaridade e suas variantes nominativas, buscando enfatizar a correspondência entre o referencial bibliográfico conceitual pela análise de textos sobre inter/multi/pluri/transdisciplinaridade com suas práticas, a fim de construir o alicerce teórico do modelo interdisciplinar a ser utilizado no projeto.

Analisaram-se, também, as proposições dos professores quanto à estruturação de sua disciplina, a fim de se verificar possíveis integrações de áreas de conhecimento, vinculadas aos núcleos de competência, bem como integração conceitual entre disciplinas, além da coerência do modelo didáticopedagógico que se usava relativamente àquele do projeto político-pedagógico da escola. Utilizou-se a estratégia de análise documental, dos currículos estruturados, pela aplicação de um instrumento (ficha) de coleta de informações sobre a estrutura das disciplinas, como conteúdos, competências e habilidades, procedimentos e avaliação.

\section{Análise dos resultados}

Realizaram-se um levantamento e posterior análise das concepções que os professores possuíam sobre disciplinaridade (D), interdisciplinaridade (I), multidisciplinaridade $(\mathrm{M})$, pluridisciplinaridade $(\mathrm{P})$ e transdisciplinaridade (T). Os professores, individualmente, em um momento 1 (Mto. 1), identificaram cada uma das variantes conceituais de disciplinaridade. Em um momento posterior (Mto 2), socializaram em grupos seus posicionamentos, sendo possível, desse modo, alterá-los.

Os resultados apontam para dificuldades que os professores apresentaram para definir as diferentes concepções sobre níveis de integração curricular.

A Tabela 1 mostra que cerca de um terço dos professores não tem claramente definido para si o conceito de interdisciplinaridade, base do referencial teórico do projeto político-pedagógico. Apesar de o PPP ter sido construído na escola, depreende-se que não contou com a participação efetiva dos professores e que, como na maioria das vezes, foi gestado na coordenação pedagógica e discutido a posteriori com os professores, no momento da implementação. 


\begin{tabular}{|c|c|c|c|c|c|c|c|c|c|c|}
\hline & \multicolumn{2}{|c|}{$\begin{array}{c}\text { Definição } 1 \\
\text { D }\end{array}$} & \multicolumn{2}{|c|}{$\begin{array}{c}\text { Definição } 2 \\
\text { I }\end{array}$} & \multicolumn{2}{|c|}{$\begin{array}{c}\text { Definição } 3 \\
M\end{array}$} & \multicolumn{2}{|c|}{$\begin{array}{c}\text { Definição } 4 \\
\text { T }\end{array}$} & \multicolumn{2}{|c|}{$\begin{array}{c}\text { Definição } 5 \\
\text { P }\end{array}$} \\
\hline & $\mathrm{Mt}^{\circ} 1$ & $\mathrm{Mt}^{\circ} 2$ & $\mathrm{Mt}^{\circ} 1$ & $\mathrm{Mt}^{\circ} 2$ & $\mathrm{Mt}^{\circ} 1$ & $\mathrm{Mt}^{\circ} 2$ & $\mathrm{Mt}^{\circ} 1$ & $\mathrm{Mt}^{\circ} 2$ & $\mathrm{Mt}^{\circ} 1$ & $\mathrm{Mt}^{\circ} 2$ \\
\hline D & $82,05 \%$ & $87,18 \%$ & 0 & 0 & $35,90 \%$ & $15,38 \%$ & $2,56 \%$ & 0 & $5,13 \%$ & 0 \\
\hline I & $5,13 \%$ & 0 & $58,97 \%$ & $66,67 \%$ & $7,69 \%$ & $5,13 \%$ & $12,82 \%$ & $2,56 \%$ & $15,38 \%$ & $17,95 \%$ \\
\hline$M$ & $5,13 \%$ & $2,56 \%$ & $25,64 \%$ & $7,69 \%$ & $38,46 \%$ & $48,72 \%$ & $7,69 \%$ & 0 & $10,26 \%$ & $15,38 \%$ \\
\hline$T$ & $2,56 \%$ & 0 & $2,56 \%$ & 0 & $2,56 \%$ & 0 & $74,36 \%$ & $84,62 \%$ & $12,82 \%$ & 0 \\
\hline$P$ & $2,52 \%$ & 0 & $10,26 \%$ & $7,69 \%$ & $15,38 \%$ & $15,38 \%$ & $2,56 \%$ & 0 & $53,85 \%$ & $51,28 \%$ \\
\hline Branco & $2,56 \%$ & $10,26 \%$ & 0 & $15,38 \%$ & 0 & $15,38 \%$ & 0 & $12,82 \%$ & 0 & $15,38 \%$ \\
\hline $\mathrm{I} / \mathrm{M}$ & 0 & 0 & $2,56 \%$ & 0 & 0 & 0 & 0 & 0 & 0 & 0 \\
\hline I/P & 0 & 0 & 0 & $2,56 \%$ & 0 & 0 & 0 & 0 & $2,56 \%$ & 0 \\
\hline
\end{tabular}

Uma análise das respostas dos professores permite verificar as diferentes opções que fizeram na escolha do texto ${ }^{7}$ com sua respectiva identificação com uma das variantes conceituais sobre integração curricular, o que pode ser observado na Tabela 1.

No que diz respeito à interdisciplinaridade, pode-se perceber que, no momento 1, 58\% dos professores possuíam um conceito de interdisciplinaridade próximo ao conceito de referência. Com o desenrolar das discussões, viu-se que, num segundo momento, $40 \%$ dos professores mantiveram o seu conceito, $26 \%$ se aproximaram do conceito formal, mas, nesse processo, $19 \%$ tiveram o seu conceito desestabilizado e dificuldades para chegar ao novo conceito. Ou seja, a discussão com os pares, num segundo momento, causou uma desestabilização, mas ainda não promoveu a estabilização de um novo conceito, exatamente por ser um processo.

Como se pode observar no Diagrama 3, os professores possuem entendimentos diferentes da integração disciplinar, mas a todas essas integrações atribuem o nome interdisciplinaridade. No decorrer dos debates, buscou-se rever esses conceitos e aproximá-los a um conceito de referência de interdisciplinaridade para, com isso, entender e definir melhor os modos de pôr em prática o projeto político-pedagógico da escola e construir seu próprio conceito localizado. No entanto, um terço dos professores teve dificuldades e não chegou a esse conceito. Por exemplo, 3\% dos professores 
conceituavam interdisciplinaridade como se fosse multidisciplinaridade no momento 1 (linha pontilhada no diagrama) e mudaram o conceito, passando a conceituar interdisciplinaridade como se fosse pluridisciplinaridade no momento 2. Por outro lado, alguns professores conceituaram interdisciplinaridade como se fosse pluridisciplinaridade no momento l, e, após as discussões, não mudaram esse conceito.

Diagrama 3

Diferentes processos de entendimento 8 do conceito interdisciplinaridade pelos professores

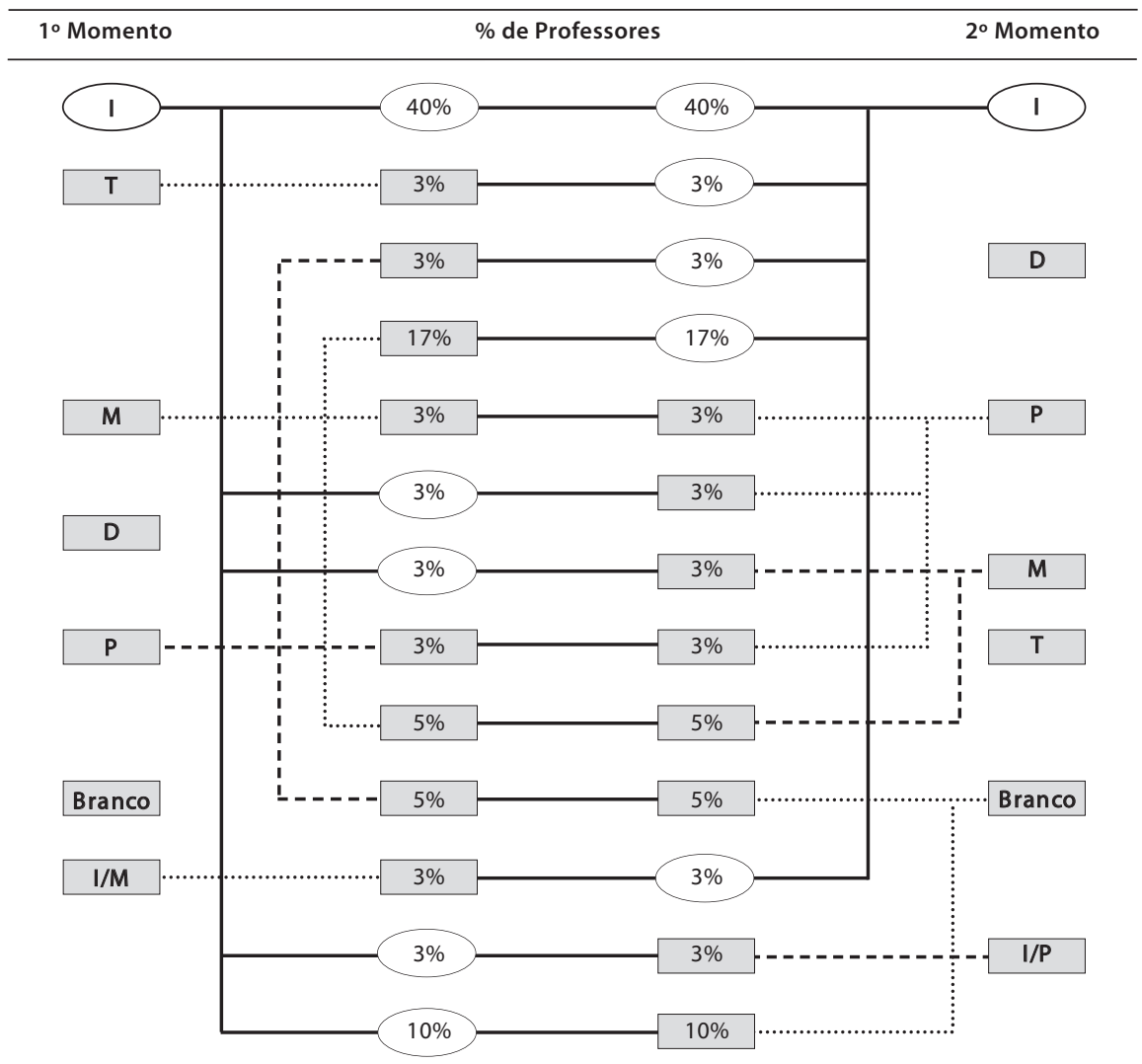

Correto

Incorreto

É importante ressaltar que a socialização das escolhas junto a seus pares permitiu um aprofundamento conceitual, elevando o número de professores que identificam a disciplina e suas variantes de acordo com o referencial teórico estudado de $40 \%$ para $66 \%$. Referencial esse construído nas reuniões do grupo e definido a partir da leitura de pequenos textos com conceituação de diferentes autores sobre as possibilidades de ruptura e integração curricular. As explicitações que se seguiram durante as reuniões 
pedagógicas possivelmente permitiram que, ao final delas, tivéssemos um grupo com um entendimento adequado sobre variantes conceituais de um currículo interdisciplinar, condição fundamental para se continuar o trabalho de estruturação do currículo da escola identificado com a dimensão conceitual de um currículo interdisciplinar. Esta estratégia se constituiu num momento de formação continuada de professores na sua realidade de escola.

A análise das proposições dos professores quanto à estruturação de sua disciplina, buscando verificar possíveis integrações de áreas de conhecimento, através da integração conceitual entre disciplinas, mostra que há um esforço dos professores, em nível proposicional, de aproximar as abordagens dos conteúdos. Por exemplo, quando se analisa as disciplinas do quinto semestre do curso de patologia clínica, algumas articulações possíveis podem ser apontadas: há uma integração entre os modelos atômicos explicativos da natureza elétrica da matéria (tópicos da disciplina de Física), com o estudo da dissociação ou ionização de substâncias quando dissolvidas em água, e os potenciais de oxi-redução, na disciplina de Química, e a transmissão neuronal, na disciplina de Anatomia. Por sua vez, os potenciais de oxi-redução são utilizados na disciplina de Bioquímica para explicar as transformações que ocorrem com os substratos no ciclo de Krebs e na cadeia respiratória. Em outra via se integram conteúdos sobre morfologia e patologia de vírus, na disciplina de Microbiologia, com aqueles de biologia celular, código genético, divisão celular e hereditariedade, com outros de anatomia, sistema reprodutor, métodos anticonceptivos e DSTs.

Com relação à coerência entre o modelo didático-pedagógico que os professores estavam usando e o projeto político-pedagógico da escola, identificou-se, quanto à metodologia de ensino, que ainda está muito centrada na aula expositiva dialogada, pois $25 \%$ dos professores indicam a utilização deste procedimento didático em suas aulas. Preferem utilizar recursos audiovisuais $(15 \%)$ àqueles informatizados $(2 \%)$, ou as visitas, palestras e aula experimental $(10 \%)$. A preferência por estes recursos vai orientar as propostas de avaliação da aprendizagem dos estudantes. Vinte por cento dos professores utilizavam exclusivamente provas com critérios quantificadores como instrumento de avaliação. Verifica-se também que os professores diversificam estes instrumentos, considerando apresentação de trabalhos e relatórios, participação em aula, entre outros. Na proposta pedagógica da escola se considera que a avaliação deve ser contínua e cumulativa e que privilegia aspectos qualitativos para a definição de aprovação ou não do estudante. É importante salientar que a seleção de conteúdos, os procedimentos metodológicos e a avaliação se estruturam a partir das competências e habilidades que se quer alcançar para a formação de um técnico na área de saúde. Os professores tiveram muita dificuldade de fazer estas relações, 
confundindo, por exemplo, instrumentos de avaliação ou tempos e momentos de avaliação, com a descrição de critérios avaliativos das competências e habilidades a serem alcançadas. Por exemplo, um professor propõe, como competência, "compreender a célula como a unidade morfofisiológica da vida, reconhecendo os diferentes tipos de organização celular e suas respectivas estruturas e funções", evidenciando assim o seu entendimento de quais competências são importantes para esse tópico. No entanto, explicita como avaliação "provas escritas, individual e em grupo; o aluno deverá atingir $70 \%$ dos objetivos propostos nos diversos procedimentos", privilegiando o instrumento de avaliação em detrimento dos critérios dessa avaliação. Em outro exemplo, o professor coloca a competência “identificar as patologias em decorrência do mau funcionamento das células sangüíneas para diagnóstico e tratamento das doenças" e novamente explicita a avaliação como "permanente durante a aula", agora privilegiando os aspectos relativos aos tempos e momentos sem indicar o que é importante ser observado durante esse processo para avaliar o quanto se alcançou a competência.

\section{Considerações finais}

A avaliação da proposta de construção de um currículo interdisciplinar na Escola Técnica de Saúde no Hospital de Clínicas de Porto Alegre indica que este processo se constitui numa estratégia de formação dos professores na sua realidade de escola. A revisão e estruturação das compreensões dos professores sobre a natureza interdisciplinar de um currículo para cursos técnicos na área da saúde permitiram a construção de uma proposta que viabilizasse a operacionalização do projeto político-pedagógico da escola, nas diferentes disciplinas que formam tal currículo.

O trabalho da Área de Educação em Química (AEQ) junto à escola foi um longo processo de aprendizagens mútuas. Neste texto explicitamos um dos muitos movimentos de pesquisa e estudos realizados, qual seja o entendimento de que a escola em seu PPP explicita por interdisciplinaridade e o que os professores pensam sobre a mesma. Nos dois momentos aqui analisados, mostramos que há tantos entendimentos de interdisciplinaridade quantas variáveis nominativas e que era necessário entender e criar um conceito específico para os objetivos da escola em seu PPP e a prática docente possível.

Fez-se, portanto, um segundo momento de pesquisa onde os professores, trocando seus entendimentos e próximos à literatura sobre as possíveis formas de integração, repensaram seus conceitos iniciais em busca de um novo, melhor compartilhado com o grupo de professores. Pelos resultados quantitativamente mostrados nos diagramas percebe-se o processo de 
construção e a dificuldade dos professores para construírem um conceito comum. Estes dados nos mostram o quão importante é a ação de problematizar e discutir conceitos curriculares com os professores, pois somente dessa forma e num processo se pode passar de palavras com significados turvos e vazios a uma ação docente diferenciada e um pouco mais próxima de um identidade curricular e de escola, como se pretendeu fazer na ETS.

\section{Notas}

1 Professor de química da Escola Estadual Técnica em Saúde do Hospital de Clínicas de Porto Alegre (ETS-HCPA), Porto Alegre, Rio Grande do Sul, Brasil. Mestre em Educação em Ciências: Química da Vida e Saúde pela Universidade Federal do Rio Grande do Sul (UFRGS). <paulo.gdavila@terra.com.br>

Correspondência: Universidade Federal do Rio Grande do Sul, Instituto de Química, Departamento de Química Inorgânica, Avenida Bento Gonçalves, 9.500, Porto Alegre, Rio Grande do Sul, Brasil, CEP 91501-970.

2 Professora adjunta da Universidade Federal do Rio Grande do Sul (UFRGS), Porto Alegre, Rio Grande do Sul, Brasil. Doutora em Ciências Biológicas - Bioquímica pela Universidade Federal do Rio Grande do Sul. <rochele-loguercio@yahoo.com.br>

3 Professor associado da Universidade Federal do Rio Grande do Sul (UFRGS), Porto Alegre, Rio Grande do Sul, Brasil. Pós-doutorado em ensino de química pela Universidade de Aveiro, Portugal. <aeq@iq.ufrgs.br>

4 Professor de química da Escola Estadual de Ensino Médio Japão, Porto Alegre, Rio Grande do Sul, Brasil. Licenciado em Química pela Universidade Federal do Rio Grande do Sul (UFRGS). <fabianofss@gmail.com>

${ }^{5}$ As formas de nomear a integração curricular não serão analisadas neste texto, pois o projeto prevê trabalhar com os professores apenas o conceito de interdisciplinaridade. Os demais são aqui apresentados para trazer aos professores a possibilidade de os mesmos estarem construindo conceitos que efetivamente não são o que a literatura denomina de interdisciplinaridade.

6 É importante destacar que, apesar de existir no PPP uma definição de interdisciplinaridade formal, esta não era necessariamente entendida e compartilhada pelos professores. Não se tentou promover um conceito formal de interdisciplinaridade com os professores, mas construir um conceito comum à escola, dado que nem mesmo, como já vimos, os pesquisadores do termo têm um conceito comum.

7 Foi entregue aos professores pequenos textos retirados da literatura, onde se evidenciavam conceitos de pesquisadores educacionais para cada um dos termos de integração disciplinar. Os professores deveriam associar o texto ao seu entendimento de interdisciplinaridade. Nesse sentido, podemos verificar pela tabela as associações dos professores. 
$8 \mathrm{O}$ entendimento de inter/pluri/multi/transdisciplinaridade está sendo avaliado em relação aos conceitos dos autores estudados nos textos pelos professores, quais sejam: Hilton Japiassu, Ivani Fazenda e Jurjo Torres Santomé. Enfatiza-se que o conceito de interdisciplinaridade está sendo estudado para que a escola construa o seu conceito comum do termo.

\section{Referências}

ARNAY, José. Reflexiones para un debate sobre la construcción del conocimiento en la escuela: hacia una cultura científica escolar. In: RODRIGO, María José; ARNAY, José. La construcción del conocimiento escolar. Barcelona: Paidós Ibérica, 1997.

CAÑAL, Pedro et al. Investigar en la escuela: elementos para una enseñanza alternativa. Sevilla: Díada, 1997.

CARRETERO, Mario. Construtivismo e educação. Porto Alegre: Artes Médicas, 1997.

DEL PINO, José Claudio et al. Proposta de ensino compatível com as características das cidades periféricas da grande Porto Alegre, Inepe, Série Documental: Relatos de Pesquisa, v. 26, p. 9-21, 1995.

DELVAL, Juan. Tesis sobre el constructivismo. In: RODRIGO, María José; ARNAY, José. La construcción del conocimiento escolar. Barcelona: Paidós Ibérica, 1997.

DEMO, Pedro. Formação de formadores básicos. Em Aberto, v. 54, p. 23-42, 1992.

Educar pela pesquisa. Campinas: Autores Associados, 1998.

ESCOLA TÉCNICA DE SAÚDE DO HOSPITAL DE CLÍNICAS DE PORTO ALEGRE. Secretaria Estadual da Educação do Rio Grande do Sul (ETS/HCPA/SERS). Projeto político-pedagógico da Escola. Porto Alegre, 2001.
FAZENDA, Ivani. Integração e interdisciplinaridade no ensino brasileiro: efetividade ou ideologia?. São Paulo: Loyola, 1996.

GIROUX, Henry. Os professores como intelectuais. Porto Alegre: Artes Médicas, 1997.

JAPIASSU, Hilton. Interdisciplinaridade e patologia do saber. Rio de Janeiro: Imago, 1976.

MÓL, Gerson S.; SANTOS, Wildson. L. P. Química na sociedade. Brasília: UNB, 1998.

PORLÁN, Rafael; GARCIA, José; CAÑAL, Pedro. Constructivismo y enseñanza de las ciencias. Sevilla: Díada, 1997.

PORLÁN, Rafael; RIVEIRO, Ana. El conocimiento de los profesores. Sevilla: Díada, 1998.

SANTOS, Wildson L. P.; SCHNETZLER, Roseli P. Educação em química: compromisso com a cidadania. Ijuí: Unijuí, 1997.

SCHÖN, Donald A. Educando o profissional reflexivo: um novo design para o ensino e a aprendizagem. Porto Alegre: Artes Médicas, 2000.

TARDIF, Maurice. Os professores face ao saber: esboço de uma problemática do saber docente. Teoria e Educação, v. 4, p. 215233, 1991. 
THIOLLENT, Michel. Metodologia da pesquisa-ação. São Paulo: Cortez, 1986.

TORRES SANTOMÉ, Jurjo. Globalización e interdisciplinariedad: el curriculum integrado. Madri: Morote, 1994.
Globalização e interdisciplinaridade. Tradução de Claudia Shilling. Porto Alegre: Artes Médicas, 1998.

Recebido em 03/07/2007

Aprovado em 04/12/2007 